\title{
1 Relationship between birth weight and chronic kidney \\ 2 disease: an integrative analysis of observational studies and \\ 3 causal inference through genetic approaches
}

4

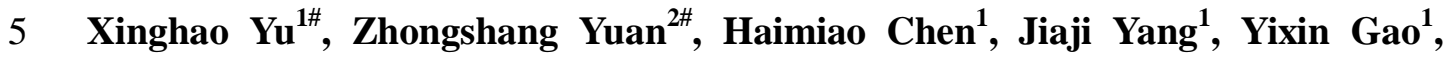

6 Fengjun Guan ${ }^{3}$, Ping Zeng ${ }^{1^{*}}$, Shuiping Huang ${ }^{1^{*}}$

7

$8{ }^{1}$ Department of Epidemiology and Biostatistics, School of Public Health, Xuzhou

9 Medical University, Xuzhou, Jiangsu, 221004, China

$10{ }^{2}$ Department of Biostatistics, School of Public Health, Shandong University, Jinan,

11 Shandong, 250012, China

$12{ }^{3}$ Department of Pediatrics, Affiliated Hospital of Xuzhou Medical University, Xuzhou, 13 Jiangsu 221004, China

14

$15{ }^{\#}$ The authors wish it to be known that, in their opinion, the first two authors should be 16 regarded as joint first authors.

18 Correspondence to

19 zpstat@xzhmu.edu.cn

20 Ping Zeng

21 hsp@xzhmu.edu.cn

22 Shuiping Huang 


\section{ABSTRACT}

25 Objective: Although many observational studies have shown that there was an inverse association between birth weight and chronic kidney disease (CKD) in adults, whether such association is causal remains largely unclear.

Methods: We first conducted a systematic review and meta-analysis to investigate the association between birth weight and CKD. Then using a set of valid instrumental variables for birth weight, we performed a two-sample Mendelian randomization (MR) to evaluate its causal effect on CKD based on summary association statistics available from large scale genome-wide association study (GWAS) (up to 143,677 individuals for birth weight and 118,147 individuals for CKD). We further validated the MR results with extensive sensitive analyses.

Results: The results of meta-analysis showed that individuals with low birth weight have about $76 \%$ (95\% CI 36 126\%) higher risk of CKD in late life compared with those with normal birth weight. Depending on 26 instrumental variables, the inverse variance weighted MR showed that the odds ratio per one SD increase of birth weight on CKD was estimated to be 0.91 (95\% CI 0.72 1.14, $p=0.396$ ). The similar null association between birth weight and $\mathrm{CKD}$ is also observed using the weighted median method and maximum likelihood method as well as the Egger regression. Such non-significant association is robust against potential instrumental outliers and pleiotropic effects.

Conclusion: Our study identifies an inverse association between birth weight and adult CKD in observational studies, while it is not supportive of the causal role of birth weight on CKD based on our MR analysis.

Keywords: Birth weight; Chronic kidney disease; Mendelian randomization; Causal association; Genome wide association study 


\section{Introduction}

Chronic kidney disease (CKD) is a common complex disease which influences both children and adult populations (Levey et al., 2015; Webster et al., 2017). At the initial disease stage, CKD is asymptomatic and may be ignored by sufferers. It is common that the diagnosis of CKD is made when disease symptoms already become severe. Moreover, a series of severe complications (e.g. renal failure, hypertension, cancer, infection and coronary heart disease) can occur with the decreased renal function of CKD patients (Di Lullo et al., 2015; Webster et al., 2017). Additionally, due to the decreased GFR during the disease progression as well as possible complications, the life quality of CKD patients is significantly lower than that of the general population.

It is estimated that the global prevalence of CKD ranges between $11 \%$ and $13 \%$, and that CKD can account for $1.5 \%$ death worldwide, making it among the leading death risk and a global public health issue (Hill et al., 2016). World Health Organization (WHO) predicts that the deaths attributable to kidney-related diseases will increase by $31 \%$ (from $\sim 871,000$ in 2015 to $\sim 1,143,000$ in 2030) in the next decade due to the growing disease rate and aging population (Organization, 2018). Therefore, identifying the risk factors of CKD can promote our understanding of the pathogenesis of this disease, having the potential to ultimately lead to better prevention and treatment for $\mathrm{CKD}$, and is also important in terms of the public health perspective (Luyckx and Brenner, 2015; Luyckx et al., 2017; Webster et al., 2017).

CKD has complicated etiologies and both genetic and non-genetic (e.g. lifestyle and environmental) risk factors to play an important role in the development of CKD (Jha et al., 2013; Webster et al., 2017; Iwagami et al., 2018; Wang et al., 2018). Some non-genetic risk factors (e.g. diabetes, hypertension, dyslipidemia and glomerulonephritis) were previously discovered in observational studies. Additionally, multiple genes (e.g. NAT8, SLC7A9, UMOD, SHROOM3, GATM and MYH9) were also identified to be associated with CKD and kidney-related traits (Chambers et al., 2010; Köttgen et al., 2010; Pattaro et al., 2016). More recently, several epidemiological studies have shown that CKD may originate from the life of the fetus — a generalized hypothesis referred to as the fetal origins hypothesis first proposed by the British epidemiologist David Barker in 1990 (thus also known as Barker 
hypothesis) (Barker, 1990; Luyckx and Brenner, 2015). The fetal origins hypothesis supposes that the risk for chronic non-communicable diseases (e.g. CKD and cardiovascular diseases) in later life can be partly attributed to the altered developmental programming and the long-term adverse adaptations to early undernutrition, both of which can lead to the structural and functional changes in multiple developing tissues and organs (Zeng et al., 2019b; Zeng and Zhou, 2019a). In the literature, birth weight is a widely used measurement for intrauterine environment; and low birth weight often serves as an indicator of impaired renal development in utero when investigating the influence of early growth on kidney-related outcomes. Although most previous studies (White et al., 2009; Luyckx and Brenner, 2015; Das et al., 2016), along with some animal experimental models (Barnett et al., 2017), illustrated that low birth weight was associated with an increased risk of CKD; owing to the heterogeneity in disease onset age, geographic diversity and ethnic differences, a few of other studies did not support the existence of the inverse relationship between birth weight and CKD (Fagerudd et al., 2006; Haysom et al., 2007), and sometimes even reported contradictory findings (Vasarhelyi et al., 2000). For example, no early glomerular and tubular damage was observed in young men with low birth weight compared with those with normal birth weight (Vasarhelyi et al., 2000).

The inconsistent observations regarding the relationship between birth weight and CKD may be also partly due to uncontrolled/unknown confounders which are commonly encountered in observational studies. Indeed, there are studies which suggested that the impaired kidney function in adulthood may be a consequence of high blood pressure (Vasarhelyi et al., 2000). Thus, it remains a concern when interpreting the observed relationship between birth weight and CKD as a causal association. A cohort longitudinal study may alleviate such concern and offer an important insight into the causal interpretation. However, longitudinal studies require large scale subjects and need very long-term follow-ups before CKD clinical presentation. Traditionally, randomized controlled trials (RCT) studies are the gold standard for inferring the causal effect of exposure on outcome. However, determining the causal relationship between birth weight and CKD by RCT is infeasible. It seems that the validation of the fetal origins hypothesis for CKD is extremely difficult in a traditional manner. 
112 In observational studies Mendelian randomization (MR) can help clarify the causal 113 relationship between an exposure of interest and an outcome, and provide an efficient 114 way for causal inference. Briefly, MR is a special instrumental variable method that 115 employs genetic variants (e.g. single nucleotide polymorphisms (SNPs)) as 116 instruments for an exposure (i.e. birth weight) and evaluates its causal effect on the 117 outcome (i.e. CKD). In the past ten years the great success of genome-wide 118 association studies (GWASs) makes it feasible to select suitable SNPs as effective 119 instruments for causal inference in MR. In fact, MR has recently become a 120 considerably popular approach of inferring causal relationship in observational 121 research (Mokry et al., 2015; Zeng et al., 2019a; Zeng and Zhou, 2019b). Indeed, birth 122 weight has been confirmed to be causally associated with many adult diseases (e.g. 123 cardiovascular disease (Au Yeung et al., 2016; Zanetti et al., 2018) and type 2 diabetes 124 (Wang et al., 2016)) through MR studies.

125 Motivated by those previous observations above, our main goal in this study was two 126 aspects. First, to illuminate whether there exists an association between birth weight 127 and CKD, we employed the systematic review and meta-analysis to provide a pooled 128 conclusion. The result showed that birth weight is inversely associated with CKD, 129 confirming the finding in other studies (Lackland et al., 2000; Fan et al., 2006; Al 130 Salmi et al., 2008; Oster et al., 2013; Hirano et al., 2016). Furthermore, to determine 131 whether this observed negative association is causal, we performed a largest and most 132 comprehensive MR analysis based on summary statistic data available from 133 large-scale GWASs with approximately 143,000 individuals for birth weight and $134 \sim 118,000$ individuals for CKD. 


\section{Materials and Methods}

\section{Systematic reviews and meta-analysis}

137 Data sources and search strategies for previous studies

138 Following the guideline of preferred reporting items for systematic reviews and meta-analyses (PRISMA) (Moher et al., 2009), we performed a literature search mainly on PubMed from January 1998 to April 2019 for articles on the relationship

141 between birth weight (and related factors including premature birth and fetal

142 development) and CKD. We made no restriction on study designs and considered both

143 cohort and population-based studies; but we limited articles in English. Originally, a

144 total of 2,072 articles (2,067 articles by searching and additional 5 articles by 145 references scanning) were obtained (Fig. S1). The following exclusion criteria for

146 articles filtering were employed: (1) the title and abstract did not contain any data on 147 birth weight and/or CKD; (2) insufficient results were available on birth weight and 148 CKD; (3) duplicated studies; (4) articles were a review, letter-to-editor, response or 149 commentary article; and (5) articles were about clinical drug trials for CKD; (6) 150 articles were about CKD in childhood. Based on those criteria, 20 studies were left in 151 our final meta-analysis.

\section{Data extraction and Statistical analysis in meta-analysis}

153 For each article that was incorporated into our meta-analysis, two investigators $(\mathrm{XH}$

154 and PZ) independently carried out data extraction and quality assessment. From each 155 article we extracted the information about study setting and design, population and 156 sample size for case and control, effect size (e.g. odds ratio (OR), relative ratio (RR) 157 or hazard ratio (HR)) as well as covariates that were adjusted for in the original 158 analysis. The effect size heterogeneity among studies was tested by the Cochran's Q 159 statistic (Thompson and Sharp, 1999). We estimated the combined effect of birth 160 weight on CKD using a weighted meta-analysis method and evaluated the published 161 bias by the Egger method and funnel plot (Egger et al., 1997). We also performed a 162 leave-one-out (LOO) analysis to assess the influence of a single study. 


\section{MR analysis}

164 GWAS data sources for birth weight and CKD

165 In our meta-analysis above we found that there exists a robust inverse association 166 between birth weight and CKD (see below for more details). To examine whether this 167 identified association is causal, we further performed a MR analysis based on large 168 scale GWAS genetic data of birth weight and CKD. To achieve this, we first yielded 169 the genetic data of birth weight from the Early Growth Genetics (EGG) consortium 170 (http://egg-consortium.org) (Horikoshi et al., 2016). In this study, birth weight was 171 measured as a continuous variable and an additive linear regression was adopted for 172 each SNP to detect its association with birth weight while controlling for available 173 covariates (e.g. gestational age). After quality control of SNP genotypes and 174 individuals, it contained summary association statistics (e.g. effect allele, marginal 175 effect size, standard error, $p$ value and sample size) for 16,245,523 genotyped and 176 imputed SNPs on 143,677 individuals of European ancestry.

177 We next obtained the summary association statistics (e.g. marginal effect size, 178 standard error and $\mathrm{p}$ value) of $\mathrm{CKD}$ from the CKDGen consortium 179 (http://ckdgen.imbi.uni-freiburg.de/) (Pattaro et al., 2016). After quality control a total 180 of 118,147 European individuals (12,385 cases and 105,762 controls) and 2,191,883 181 SNPs were available for this CKD GWAS. Besides CKD, we also attempted to 182 explore the causal relationship between birth weight and other kidney-related 183 phenotypes which included eGFR based on serum creatinine (eGFRcrea) and cystatin 184 C (eGFRcys) (Pattaro et al., 2016), annual decline of eGFR (eGFR change) and rapid 185 eGFR decline (Rapid Decline) (Gorski et al., 2015), urinary albumin-to-creatinine 186 ratio (UACR) and microalbuminuria (MA) (Teumer et al., 2016). The used GWAS 187 genetic data sets in our MR study are summarized in Table S1. Since participants had 188 given informed consent for data sharing as described in each of the original GWASs

189 and only summary association results were employed; therefore, ethical review was 190 not needed for our study.

191 Estimation of causal effect of birth weight on CKD and sensitivity analyses

192 We then employed MR approaches to determine the causal relationship between birth 193 weight and CKD. First, to ensure the validity of MR we carefully selected a set of 194 independent index associated $(p<5.00 \mathrm{E}-8)$ SNPs that can serve as valid instrumental 
195 variables for birth weight. The summary information of those index SNPs for birth

196 weight and CKD are shown in Table S2. Next, to quantitatively check whether the

197 selected instruments for birth weight are strong, we calculated the proportion of

198 phenotypic variance of birth weight explained by each instrument and computed the $F$

199 statistic as an empirical indicator of strong/weak instrument (Noyce et al., 2017). We

200 then performed the two-sample inverse-variance weighted (IVW) MR methods

201 (Burgess et al., 2017) to estimate the causal effect of birth weight on CKD in terms of

202 per standard deviation (SD) change in birth weight, where the SD of birth weight was

203 estimated to be about 488 grams (Horikoshi et al., 2016). Before the causal effect

204 estimation, to further ensure the validity of MR, we inspected the pleiotropic

205 associations by removing instruments that may be potentially related to CKD with an

206 adjusted $\mathrm{p}$ value less than 0.05 after Bonferroni correction. In our analysis no

207 instruments were excluded by this conservative manner. To examine the robustness of

208 results in the MR analysis, we carried out several sensitivity analyses: (1) weighted

209 median-based method (Bowden et al., 2016) and maximum likelihood method

210 (Burgess et al., 2013); (2) LOO analysis (Noyce et al., 2017) and MR-PRESSO test

211 (Verbanck et al., 2018) to validate instrumental outliers that can substantially impact

212 the causal effect estimate; (3) MR-Egger regression to detect directional pleiotropic

213 effects of instrument variables (Burgess and Thompson, 2017). 


\section{Result}

\section{Combined effect of birth weight on CKD in systematic review and meta-analysis}

216 A total of 20 studies satisfied the inclusion criteria and were finally incorporated into 217 our systematic review and meta-analysis (Fig. S1). Most of the included studies were 218 carried out on European individuals. The extracted information of those studies is 219 shown in Table 1. All the studies reported the risk of CKD for low birth weight 220 compared with normal birth weight, and nine additionally reported the risk of CKD 221 for high birth weight compared with normal birth weight. Note that the definition of 222 low/high birth weight was slightly different across studies (see Table 1 for more 223 details). Among those, 16 studies showed that low birth weight can increase the risk 224 of CKD in later life. Additionally, five out of nine studies demonstrated that high birth 225 weight can also raise the risk of CKD. Those results suggested that there may exist a 226 U-shaped relationship between birth weight and CKD. We thus performed 227 meta-analysis for the association between low or high birth weight with CKD 228 separately (Fig. 1).

229 Owing to the presence of heterogeneous effect size of birth weight on CKD in those 230 studies (the $\mathrm{p}$ values of the Q statistic are less than 0.05 for both low and high birth 231 weight; Fig. 1), the results of the random-effects meta-analysis are displayed here. 232 Specifically, we found that the risk of CKD for adult individuals with low birth weight 233 is $76 \%(\mathrm{OR}=1.76,95 \% \mathrm{CI} 1.37 \sim 2.26, p=1.27 \mathrm{E}-5)$ higher compared with those with 234 normal birth weight (Fig. 1A), implying that lower birth weight leads to more 235 vulnerable to $\mathrm{CKD}$. This inverse relationship also holds in the sub-group 236 meta-analyses in terms of gender or the type of study design (Fig. S2-S3). However, 237 no significant association is observed between high birth weight and CKD $(\mathrm{OR}=1.05$, $23895 \%$ CI $0.81 \sim 1.37, p=0.713$; Fig. 1B). These results are robust according to the LOO 239 analyses which show that no single study can substantially dominate the final 240 combined estimates (Table S3-S4). Additionally, the Egger test ( $p=0.170$ for low birth 241 weight and $p=0.982$ for high birth weight), together with the funnel plot (Fig. S2), 242 demonstrates that the publication bias is less likely to influence the combined 243 estimates in our meta-analysis. In summary, based on the results of meta-analysis 244 above, we can conclude that an inverse association exists between birth weight and $245 \mathrm{CKD}$, but no evidence is present for the observed U-shaped relationship. 


\section{Estimated causal effect of birth weight on CKD}

247 In our MR analysis, a total of 26 independent index SNPs served as instrument 248 variables for birth weight. They jointly explain a total of $0.91 \%$ of phenotypic 249 variance for birth weight. The $F$ statistics of those instruments range from 27.6 to 250175.6 (with an average of 49.26), indicating that the weak instrument bias does not 251 likely occur in our analysis. Little evidence of causal effect heterogeneity across 252 instruments is observed $(\mathrm{Q}=23.08$ and $p=0.573)$; therefore, we employed the 253 fixed-effects IVW MR method to estimate the causal effect and found that there exists 254 a negative but non-significant casual association between birth weight and CKD. 255 More specifically, the OR per one SD increase of birth weight on CKD is 0.91 (95\% 256 CI 0.72 1.14, $p=0.396$ ), consistent with those produced by the weighted median method $(\mathrm{OR}=0.86,95 \%$ CI $0.62 \sim 1.18, p=0.346)$ and by the maximum likelihood approach $(\mathrm{OR}=0.91,95 \%$ CI $0.72 \sim 1.14, p=0.414)$. The similarly null causal association was also observed if we employ other sets of instrumental variables for birth weight (Supplementary File). In addition, we also did not discover a significant casual association between birth weight and other kidney-related traits (Fig. S5).

We next examined whether there are potential instrument outliers and whether these outliers have a substantial influence on the estimate of causal effect. To do so, we created a scatter plot by drawing the effect sizes of SNPs of birth weight against those

265 SNPs of CKD for all the used instruments (Fig. 2A). It is shown that no instrumental 266 variables can be considered potential outliers. The result of MR-PRESSO also 267 displays that there do not exist instrument outliers at the significance level of 0.05 .

268 Consistently, in terms of the result of the LOO analysis, no single instrument can have a substantial influence on the estimation of causal effect (Table S5). The OR per one SD increase of birth weight on CKD is estimated to be 0.55 (95\% CI 0.26 1.17, $271 p=0.120$ ) using the MR-Egger regression. Furthermore, the MR-Egger regression 272 removes the possibility of pleiotropic effects of instrument variables (the 273 intercept $=0.015,95 \%$ CI $-0.007 \sim 0.037, p=0.174)$. The funnel plot also presents a 274 symmetric pattern around the causal effect point estimate (Fig. 2B), further indicating 275 the absence of horizontal pleiotropy. Overall, the MR results do not provide 276 statistically significant evidence that supports the direct causal association between 277 birth weight and CKD. 


\section{Discussion}

279 To understand the relationship between birth weight and CKD, in the present study we 280 first performed a systematic review and meta-analysis. The results showed that 281 individuals with low birth weight would have a higher risk of CKD in adulthood 282 compared with those with normal weight, in line with previous observation (Poulter et 283 al., 1999; Al Salmi et al., 2007; Khalsa et al., 2016). The mechanism underlying this 284 inverse association between birth weight and CKD is very complicated (Di Lullo et al., 285 2015; Webster et al., 2017). Possible interpretations include the finding that low birth 286 weight can lead to the reduction of the number of kidney nephrons (Luyckx et al., 287 2013). For example, it was observed that every $1 \mathrm{~kg}$ decrease of birth weight can 288 result in about 250,000 reduction in the number of unilateral nephrons (Hoy et al., 289 2005). The relatively smaller number of nephrons for individuals with low birth 290 weight implies a higher susceptibility to kidney diseases in later life (Brenner et al., 291 1988; Luyckx et al., 2017). This finding was also supported by animal models which 292 showed that offspring had decreased kidney nephrons if being exposed to adverse 293 environmental conditions during pregnancy (Bidani et al., 2013; Horowitz et al., 294 2015). However, our results provided little evidence supporting the existence of 295 association between high birth weight and CKD although previous studies suggested 296 high birth weight can also elevate the risk of CKD.

297 To investigate whether this observed negative association between birth weight and 298 CKD in our meta-analysis is causal, we further carried out a two-sample MR analysis 299 based on summary statistics publicly available from large scale GWASs. Because MR 300 relies on the Mendel's second law which means that an allele of a gene can enter a 301 gamete independently of another gene. Therefore, MR is less likely affected by 302 confounding factors compared with observational studies (Burgess et al., 2017). In 303 our MR analysis, to improve the statistical power and meet the model assumptions we 304 used multiple instrument variables which were independent from each other and 305 strongly associated with birth weight. We also tried to avoid the pleiotropic effects of 306 instruments by removing index SNPs that may be potentially related with CKD. 307 Further sensitive analyses (e.g. Egger regression) also excluded the likelihood of 308 pleiotropy that can introduce bias into the causal effect estimation. However, the 309 results of MR did not offer statistically significant evidence supporting the direct 
310 causal relationship between birth weight and CKD.

311 Several explanations exist in this observed association. Especially, after birth the 312 threat to the survival of the nephron still exists. Infants with low birth weight are often 313 accompanied by a decrease in the number of nephrons due to impaired renal function 314 development. The decrease in the number of nephrons may result in glomerular 315 hypertrophy and high filtration rate, which ultimately leads to secondary glomerular 316 sclerosis. As one of the important risk factors for CKD (Coca et al., 2012), acute 317 kidney injury occurs in $18-40 \%$ of very low birth weight infants (Koralkar et al., 318 2011). Additionally, most of infants with very low birth weight receive at least one 319 nephrotoxic drug treatment before discharge, which can potentially affect kidney 320 function (Rhone et al., 2014). Infants with low birth weight or limited intrauterine 321 growth often experience accelerated "catch-up" growth, which is also associated with 322 CKD (Fagerberg et al., 2004).

323 Nevertheless, we note that the estimated causal effects between birth weight and CKD 324 were consistent in the direction and magnitude through multiple MR methods (e.g. 325 IVW, weighted median method and maximum likelihood estimation). There are 326 several explanations for the failure of detecting a causal association between birth 327 weight and CKD given the observation that low birth weight is robustly related to the 328 increased risk of $\mathrm{CKD}$ in our meta-analysis. First, this inverse relationship in 329 observational studies may be driven by shared genetic components between birth 330 weight and CKD. To check this, we applied the linkage disequilibrium score 331 regression (LDSC) (Bulik-Sullivan et al., 2015) to quantify the genetic covariance 332 between birth weight and CKD. LDSC is a novel statistical genetic method for 333 quantifying genetic correlation for two traits based on the genome-wide pleiotropy 334 (note that our MR analysis has removed the influence of pleiotropic effects). With 335 LDSC, we found a pronounced but nonsignificant genetic correlation between birth 336 weight and CKD $\left(R_{\mathrm{g}}=-0.234\right.$, se $=0.081, p=0.771$; see Table S6 for more information), 337 suggesting the common polygenic risk shared by low birth weight and CKD. More 338 specifically, this means that some SNPs that are associated with low birth weight also 339 related to the risk of CKD. Second, the failure of detecting non-zero causal effect of 340 birth weight on CKD may be partly due to a lack of adequate statistical power. To 341 examine this, we performed the statistical power calculation to discover an OR of 0.80 
342 or 0.90 in the risk of CKD per unit change of birth weight following the approach

343 shown in (Brion et al., 2013). Note that, these assumed ORs approximately equal to

344 the estimated effect size of birth weight on CKD in our study. The results imply that

345 we have a small to moderate power to detect the causal association between birth

346 weight and CKD due to the small number of CKD cases (Fig. 3). For example, with

347 the current sample size of CKD in our study (i.e. assume the sample size of adult

348 CKD is 117,000 and the proportion of cases is $10.6 \%$ ), the estimated statistical power

349 is $17 \%$ or $25 \%$ to detect an OR of 0.80 or 0.90 , respectively. Third, we cannot rule out

350 the possibility that there exist some unknown pathways which mediate the influence

351 of birth weight on CKD. Note that the existence of mediation effect (or indirect effect)

352 of birth weight does not violate the model assumptions of MR. For example, it is

353 well-established that low birth weight can increase the risk of coronary heart disease,

354 diabetes and hypertension; the latter two are the major causes of CKD (Wingen et al.,

355 1997; Jafar et al., 2003; Ardissino et al., 2004; Targher et al., 2008; Jha et al., 2013),

356 implying that birth weight can have an impact on CKD by the metabolic or

357 cardiovascular pathway.

\section{$358 \quad$ Limitation}

359 Finally, some limitations of this study should be considered. First, both birth weight

360 (and all corresponding antecedents and early risk factors) and CKD are heterogeneous

361 phenotypes; for example, among adult CKDs, polycystic kidney disease is currently

362 known as a hereditary kidney disorder and is one of the most common autosomal

363 dominant diseases (Gabow, 1993; Chapman et al., 2015). Diabetic nephropathy is

364 caused by lifestyle and genetic factors and Hypertensive kidney disease is more

365 caused by environmental factors(Go et al., 2004; Vivante and Hildebrandt, 2016).

366 Therefore, when combining these heterogeneous CKDs together in analysis, a large

367 degree of deviation may be introduced in our analysis. Second, as mentioned above,

368 we have only a limited statistical power in our MR analysis due to the small sample

369 size of cases in the CKD GWAS. Third, like many previous MR studies we

370 hypothesized that there is a linear relationship between birth weight and CKD in our

371 analysis. Linearity may be unreasonable in practice since previous epidemiological

372 studies have found that high birth weight also increases the risk of CKD, implying a

373 U-type relationship between birth weight and CKD. Therefore, we cannot completely

374 remove the nonlinear influence of birth weight on CKD. Fourth, our MR relies on 
375 summary statistics rather than individual-level data sets, thus we cannot analyze the

376 relationship between very low/high birth weight and CKD due to lack of relevant data

377 information, and we are also unable to conduct stratified analyses (e.g. in terms of 378 gender; see Table 1) in our MR study.

379 In conclusion, our study identifies an inverse association between birth weight and

380 CKD in observational studies, while it is not supportive of the causal role of birth 381 weight on the risk of CKD based on our MR analysis. 


\section{Acknowledgements}

383 We thank all the EGG and CKDGen consortium studies for making the summary data 384 publicly available and we are grateful of all the investigators and participants 385 contributed to those studies. The data analyses in the present study were supported by 386 the high-performance computing at Xuzhou Medical University.

\section{Author Contributions}

388 PZ and SH conceived the idea for the study; PZ and XY obtained the data; PZ and XY 389 cleared up the datasets; PZ, XY and ZY mainly performed the data analyses; HC, YG 390 and JY helped clear and analyze the data; PZ, XY, ZY and FG interpreted the results

391 of the data analyses; PZ and XY wrote the manuscript, and other authors approved the 392 manuscript and provided relevant suggestions.

\section{Disclosure}

394 The authors declare that the research was conducted in the absence of any commercial 395 or financial relationships that could be construed as a potential conflict of interest.

\section{Funding}

397 This study was supported by the National Natural Science Foundation of Jiangsu 398 (BK20181472), Youth Foundation of Humanity and Social Science funded by 399 Ministry of Education of China (18YJC910002), the China Postdoctoral Science 400 Foundation (2018M630607 and 2019T120465), Jiangsu QingLan Research Project for 401 Outstanding Young Teachers and Six Talent Peaks Project of Jiangsu Province of 402 China (WSN-087), the Postdoctoral Science Foundation of Xuzhou Medical 403 University, the National Natural Science Foundation of China (81402765), the 404 Statistical Science Research Project from National Bureau of Statistics of China 405 (2014LY112), the Postgraduate Research \& Practice Innovation Program of Jiangsu 406 Province (KYCX19_2250), and the Priority Academic Program Development of

407 Jiangsu Higher Education Institutions (PAPD) for Xuzhou Medical University.

408 Supplementary material

409 Supplementary File. 
1. Al Salmi, I., Hoy, W., Kondalsamy-Chennakesavan, S., Wang, Z., Gobe, G., Healy, H., et al. (2007). Adult chronic kidney disease patients have lower birth weight than the general Australian population. Early Human Development 83(Supp. 1), S109-S109.

2. Al Salmi, I., Hoy, W.E., Kondalsamy-Chennakes, S., Wang, Z., Healy, H., and Shaw, J.E. (2008). Birth Weight and Stages of CKD: A Case-Control Study in an Australian Population. American Journal of Kidney Diseases 52(6), 1070-1078. doi: 10.1053/j.ajkd.2008.04.028.

3. Ardissino, G., Testa, S., Dacco, V., Vigano, S., Taioli, E., Claris-Appiani, A., et al. (2004). Proteinuria as a predictor of disease progression in children with hypodysplastic nephropathy - Data from the ItalKid Project. Pediatric Nephrology 19(2), 172-177. doi: 10.1007/s00467-003-1268-0.

4. Au Yeung, S.L., Lin, S.L., Li, A.M., and Schooling, C.M. (2016). Birth weight and risk of ischemic heart disease: A Mendelian randomization study. Scientific Reports 6, 38420. doi: 10.1038/srep38420.

5. Barker, D.J. (1990). The fetal and infant origins of adult disease. British Medical Journal 301(6761), 1111-1111. doi: 10.1136/bmj.301.6761.1111.

6. Barnett, C., Nnoli, O., Abdulmahdi, W., Nesi, L., Shen, M., Zullo, J.A., et al. (2017). Low birth weight is associated with impaired murine kidney development and function. Pediatr Res 82(2), 340-348. doi: 10.1038/pr.2017.53.

7. Berglund, D., MacDonald, D., Jackson, S., Spong, R., Issa, N., Kukla, A., et al. (2014). Low birthweight and risk of albuminuria in living kidney donors. Clinical Transplantation 28(3), 361-367. doi: 10.1111/ctr.12321.

8. Bidani, A.K., Polichnowski, A.J., Loutzenhiser, R., and Griffin, K.A. (2013). Renal microvascular dysfunction, hypertension and CKD progression. Current Opinion in Nephrology and Hypertension 22(1), 1-9. doi: 10.1097/MNH.0b013e32835b36c1.

9. Bowden, J., Smith, G.D., Haycock, P.C., and Burgess, S. (2016). Consistent Estimation in Mendelian Randomization with Some Invalid Instruments Using a Weighted Median Estimator. Genetic Epidemiology 40(4), 304-314. doi: 10.1002/gepi.21965.

10. Brenner, B.M., Garcia, D.L., and Anderson, S. (1988). Glomeruli and blood pressure. Less of one, more the other? American journal of hypertension 1(4 Pt 1), 335-347. doi: 10.1093/ajh/1.4.335.

11. Brion, M.-J.A., Shakhbazov, K., and Visscher, P.M. (2013). Calculating statistical power in Mendelian randomization studies. International Journal of Epidemiology 42(5), 1497-1501. doi: 10.1093/ije/dyt179.

12. Bulik-Sullivan, B.K., Loh, P.-R., Finucane, H.K., Ripke, S., Yang, J., Patterson, N., et al. (2015). LD Score regression distinguishes confounding from polygenicity in genome-wide association studies. Nature Genetics 47(3), 291. doi: 10.1038/ng.3211.

13. Burgess, S., Butterworth, A., and Thompson, S.G. (2013). Mendelian Randomization Analysis With Multiple Genetic Variants Using Summarized Data. Genetic Epidemiology 37(7), 658-665. doi: 10.1002/gepi.21758.

14. Burgess, S., Small, D.S., and Thompson, S.G. (2017). A review of instrumental variable estimators for Mendelian randomization. Statistical Methods in Medical Research 26(5), 2333-2355. doi: 10.1177/0962280215597579.

15. Burgess, S., and Thompson, S.G. (2017). Interpreting findings from Mendelian 
randomization using the MR-Egger method. European Journal of Epidemiology 32(5), 377-389. doi: 10.1007/s10654-017-0255-x.

16. Chambers, J.C., Zhang, W., Lord, G.M., Van Der Harst, P., Lawlor, D.A., Sehmi, J.S., et al. (2010). Genetic loci influencing kidney function and chronic kidney disease. Nature genetics 42(5), 373. doi: 10.1038/ng.566.

17. Chapman, A.B., Devuyst, O., Eckardt, K.-U., Gansevoort, R.T., Harris, T., Horie, S., et al. (2015). Autosomal-dominant polycystic kidney disease (ADPKD): executive summary from a Kidney Disease: Improving Global Outcomes (KDIGO) Controversies Conference. Kidney international 88(1), 17-27. doi: 10.1038/ki.2015.59.

18. Coca, S.G., Singanamala, S., and Parikh, C.R. (2012). Chronic kidney disease after acute kidney injury: a systematic review and meta-analysis. Kidney international 81(5), 442-448. doi: 10.1038/ki.2011.379.

19. Das, S.K., Mannan, M., Faruque, A.S.G., Ahmed, T., McIntyre, H.D., and Al Mamun, A. (2016). Effect of birth weight on adulthood renal function: A bias-adjusted meta-analytic approach. Nephrology 21(7), 547-565. doi: 10.1111/nep.12732.

20. Di Lullo, L., House, A., Gorini, A., Santoboni, A., Russo, D., and Ronco, C. (2015). Chronic kidney disease and cardiovascular complications. Heart Failure Reviews 20(3), 259-272. doi: 10.1007/s10741-014-9460-9.

21. Dyck, R., Klomp, H., Tan, L., and Stang, M.R. (2003). An association of maternal age and birth weight with end-stage renal disease in Saskatchewan - Sub-analysis of registered Indians and those with diabetes. American Journal of Nephrology 23(6), 395-402. doi: 10.1159/000074066.

22. Egger, M., Davey Smith, G., Schneider, M., and Minder, C. (1997). Bias in meta-analysis detected by a simple, graphical test. Bmj 315(7109), 629-634. doi: 10.1136/bmj.315.7109.629.

23. Eriksson, J.G., Salonen, M.K., Kajantie, E., and Osmond, C. (2018). Prenatal Growth and CKD in Older Adults: Longitudinal Findings From the Helsinki Birth Cohort Study, 1924-1944. Am J Kidney Dis 71(1), 20-26. doi: 10.1053/j.ajkd.2017.06.030.

24. Fagerberg, B., Bondjers, L., and Nilsson, P. (2004). Low birth weight in combination with catch-up growth predicts the occurrence of the metabolic syndrome in men at late middle age: the Atherosclerosis and Insulin Resistance study. J Intern Med 256(3), 254-259. doi: 10.1111/j.1365-2796.2004.01361.x.

25. Fagerudd, J., Forsblom, C., Pettersson-Fernholm, K., Saraheimo, M., Wadén, J., Rönnback, M., et al. (2006). Low birth weight does not increase the risk of nephropathy in Finnish type 1 diabetic patients. Nephrology Dialysis Transplantation 21(8), 2159-2165.

26. Fan, Z.J., Lackland, D.T., Lipsitz, S.R., and Nicholas, J.S. (2006). The Association of Low Birthweight and Chronic Renal Failure among Medicaid Young Adults with Diabetes and/or Hypertension. Public Health Reports 121(3), 239-244. doi: 10.1177/003335490612100304.

27. Gabow, P.A. (1993). Autosomal dominant polycystic kidney disease. New England Journal of Medicine 329(5), 332-342. doi: 10.1056/NEJM199307293290508.

28. Go, A.S., Chertow, G.M., Fan, D., McCulloch, C.E., and Hsu, C.-y. (2004). Chronic kidney disease and the risks of death, cardiovascular events, and hospitalization. New England Journal of Medicine 351(13), 1296-1305. doi: 10.1056/NEJMoa041031. 
29. Gorski, M., Tin, A., Garnaas, M., McMahon, G.M., Chu, A.Y., Tayo, B.O., et al. (2015). Genome-wide association study of kidney function decline in individuals of European descent. Kidney International 87(5), 1017-1029. doi: 10.1038/ki.2014.361.

30. Hallan, S., Euser, A.M., Irgens, L.M., Finken, M.J., Holmen, J., and Dekker, F.W. (2008). Effect of intrauterine growth restriction on kidney function at young adult age: the Nord Trondelag Health (HUNT 2) Study. Am J Kidney Dis 51(1), 10-20. doi: 10.1053/j.ajkd.2007.09.013.

31. Haysom, L., Williams, R., Hodson, E., Roy, L.P., Lyle, D., and Craig, J.C. (2007). Early chronic kidney disease in Aboriginal and non-Aboriginal Australian children: remoteness, socioeconomic disadvantage or race? Kidney International 71(8), 787-794. doi: 10.1038/sj.ki.5002099.

32. Hill, N.R., Fatoba, S.T., Oke, J.L., Hirst, J.A., O'Callaghan, C.A., Lasserson, D.S., et al. (2016). Global Prevalence of Chronic Kidney Disease - A Systematic Review and Meta-Analysis. Plos One 11(7). doi: 10.1371/journal.pone.0158765.

33. Hirano, D., Ishikura, K., Uemura, O., Ito, S., Wada, N., Hattori, M., et al. (2016). Association between low birth weight and childhood-onset chronic kidney disease in Japan: a combined analysis of a nationwide survey for paediatric chronic kidney disease and the National Vital Statistics Report. Nephrol Dial Transplant 31(11), 1895-1900. doi: 10.1093/ndt/gfv425.

34. Horikoshi, M., Beaumont, R.N., Day, F.R., Warrington, N.M., Kooijman, M.N., Fernandez-Tajes, J., et al. (2016). Genome-wide associations for birth weight and correlations with adult disease. Nature 538(7624), 248. doi: 10.1038/nature19806.

35. Horowitz, B., Miskulin, D., and Zager, P. (2015). Epidemiology of Hypertension in CKD. Advances in Chronic Kidney Disease 22(2), 88-95. doi: 10.1053/j.ackd.2014.09.004.

36. Hoy, W.E., Hughson, M.D., Bertram, J.F., Douglas-Denton, R., and Amann, K. (2005). Nephron number, hypertension, renal disease, and renal failure. Journal of the American Society of Nephrology 16(9), 2557-2564. doi: 10.1681/asn.2005020172.

37. Iwagami, M., Mansfield, K.E., Hayes, J.F., Walters, K., Osborn, D.P.J., Smeeth, L., et al. (2018). Severe mental illness and chronic kidney disease: a cross-sectional study in the United Kingdom. Clinical Epidemiology 10. doi: 10.2147/clep.s154841.

38. Jafar, T.H., Stark, P.C., Schmid, C.H., Landa, M., Maschio, G., de Jong, P.E., et al. (2003). Progression of chronic kidney disease: The role of blood pressure control, proteinuria, and angiotensin-converting enzyme inhibition - A patient-level meta-analysis. Annals of Internal Medicine 139(4), 244-252. doi: 10.7326/0003-4819-139-4-200308190-00006.

39. Jha, V., Garcia-Garcia, G., Iseki, K., Li, Z., Naicker, S., Plattner, B., et al. (2013). Chronic kidney disease: global dimension and perspectives. Lancet 382(9888), 260-272. doi: 10.1016/s0140-6736(13)60687-x.

40. Khalsa, D.D.K., Beydoun, H.A., and Carmody, J.B. (2016). Prevalence of chronic kidney disease risk factors among low birth weight adolescents. Pediatric Nephrology 31(9), 1509-1516. doi: 10.1007/s00467-016-3384-7.

41. Koralkar, R., Ambalavanan, N., Levitan, E.B., McGwin, G., Goldstein, S., and Askenazi, D. (2011). Acute kidney injury reduces survival in very low birth weight infants. Pediatric research 69(4), 354. doi: 10.1203/PDR.0b013e31820b95ca.

42. Köttgen, A., Pattaro, C., Böger, C.A., Fuchsberger, C., Olden, M., Glazer, N.L., et 
al. (2010). New loci associated with kidney function and chronic kidney disease. Nature genetics 42(5), 376. doi: 10.1038/ng.568.

43. Lackland, D.T., Bendall, H.E., Osmond, C., Egan, B.M., and Barker, D.J. (2000). Low birth weights contribute to high rates of early-onset chronic renal failure in the Southeastern United States. Arch Intern Med 160(10), 1472-1476.

44. Lackland, D.T., Egan, B.M., Fan, Z.J., and Syddall, H.E. (2001). Low birth weight contributes to the excess prevalence of end-stage renal disease in African Americans. J Clin Hypertens (Greenwich) 3(1), 29-31. doi: 10.1111/j.1524-6175.2001.00828.x.

45. Levey, A.S., Becker, C., and Inker, L.A. (2015). Glomerular Filtration Rate and Albuminuria for Detection and Staging of Acute and Chronic Kidney Disease in Adults A Systematic Review. Jama-Journal of the American Medical Association 313(8), 837-846. doi: 10.1001/jama.2015.0602.

46. Li, S., Chen, S.C., Shlipak, M., Bakris, G., McCullough, P.A., Sowers, J., et al. (2008). Low birth weight is associated with chronic kidney disease only in men. Kidney Int 73(5), 637-642. doi: 10.1038/sj.ki.5002747.

47. Luyckx, V.A., Bertram, J.F., Brenner, B.M., Fall, C., Hoy, W.E., Ozanne, S.E., et al. (2013). Effect of fetal and child health on kidney development and long-term risk of hypertension and kidney disease. Lancet 382(9888), 273-283. doi: 10.1016/s0140-6736(13)60311-6.

48. Luyckx, V.A., and Brenner, B.M. (2015). Birth weight, malnutrition and kidney-associated outcomes-a global concern. Nature Reviews Nephrology 11(3), 135-149. doi: 10.1038/nrneph.2014.251.

49. Luyckx, V.A., Perico, N., Somaschini, M., Manfellotto, D., Valensise, H., Cetin, I., et al. (2017). A developmental approach to the prevention of hypertension and kidney disease: a report from the Low Birth Weight and Nephron Number Working Group. Lancet 390(10092), 424-428. doi: 10.1016/s0140-6736(17)30576-7.

50. Moher, D., Liberati, A., Tetzlaff, J., and Altman, D.G. (2009). Preferred reporting items for systematic reviews and meta-analyses: the PRISMA statement. BMJ (Clinical Research Ed.) 339. doi: 10.1136/bmj.b2535.

51. Mokry, L.E., Ross, S., Ahmad, O.S., Forgetta, V., Smith, G.D., Leong, A., et al. (2015). Vitamin D and Risk of Multiple Sclerosis: A Mendelian Randomization Study. Plos Medicine 12(8). doi: 10.1371/journal.pmed.1001866.

52. Nelson, R.G., Morgenstern, H., and Bennett, P.H. (1998). Birth weight and renal disease in Pima Indians with type 2 diabetes mellitus. Am J Epidemiol 148(7), 650-656. doi: 10.1093/aje/148.7.650.

53. Noyce, A.J., Kia, D.A., Hemani, G., Nicolas, A., Price, T.R., De Pablo-Fernandez, E., et al. (2017). Estimating the causal influence of body mass index on risk of Parkinson disease: A Mendelian randomisation study. Plos Medicine 14(6). doi: 10.1371/journal.pmed.1002314.

54. Organization, W.H. (2018). "Mortality and global health estimates: Causes of death; Projections for 2015-2030; Projection of death rates". Geneva: WHO).

55. Oster, R.T., Luyckx, V.A., and Toth, E.L. (2013). Birth weight predicts both proteinuria and overweight/obesity in a rural population of Aboriginal and non-Aboriginal Canadians. Journal of Developmental Origins of Health and Disease 4(2), 139-145. doi: 10.1017/s2040174412000724.

56. Painter, R.C., Roseboom, T.J., Van Montfrans, G.A., Bossuyt, P.M., Krediet, R.T., Osmond, C., et al. (2005). Microalbuminuria in adults after prenatal exposure to the Dutch famine. Journal of the American Society of Nephrology 16(1), 189-194. 
doi: 10.1681/ASN.2004060474.

57. Pattaro, C., Teumer, A., Gorski, M., Chu, A.Y., Li, M., Mijatovic, V., et al. (2016). Genetic associations at 53 loci highlight cell types and biological pathways relevant for kidney function. Nature Communications 7 . doi: $10.1038 /$ ncomms 10023 .

58. Poulter, N.R., Chang, C.L., MacGregor, A.J., Snieder, H., and Spector, T.D. (1999). Association between birthweight and adult blood pressure in twins: historical cohort study. British Medical Journal 319(7221), 1330-1333. doi: 10.1136/bmj.319.7221.1330.

59. Rhone, E.T., Carmody, J.B., Swanson, J.R., and Charlton, J.R. (2014). Nephrotoxic medication exposure in very low birth weight infants. The Journal of Maternal-Fetal \& Neonatal Medicine 27(14), 1485-1490. doi: 10.3109/14767058.2013.860522.

60. Ruggajo, P., Svarstad, E., Leh, S., Marti, H.P., Reisaether, A.V., and Vikse, B.E. (2016). Low Birth Weight and Risk of Progression to End Stage Renal Disease in IgA Nephropathy--A Retrospective Registry-Based Cohort Study. PLoS One 11(4), e0153819. doi: 10.1371/journal.pone.0153819.

61. Targher, G., Chonchol, M., Bertolini, L., Rodella, S., Zenari, L., Lippi, G., et al. (2008). Increased Risk of CKD among Type 2 Diabetics with Nonalcoholic Fatty Liver Disease. Journal of the American Society of Nephrology 19(8), 1564-1570. doi: 10.1681/asn.2007101155.

62. Teumer, A., Tin, A., Sorice, R., Gorski, M., Yeo, N.C., Chu, A.Y., et al. (2016). Genome-wide Association Studies Identify Genetic Loci Associated With Albuminuria in Diabetes. Diabetes 65(3), 803-817. doi: 10.2337/db15-1313.

63. Thompson, S.G., and Sharp, S.J. (1999). Explaining heterogeneity in meta-analysis: A comparison of methods. Statistics in Medicine 18(20), 2693-2708.

doi: 10.1002/(sici)1097-0258(19991030)18:20<2693::aid-sim235>3.0.co;2-v.

64. Vasarhelyi, B., Dobos, M., Reusz, G.S., Szabo, A., and Tulassay, T. (2000). Normal kidney function and elevated natriuresis in young men born with low birth weight. Pediatr Nephrol 15(1-2), 96-100.

65. Verbanck, M., Chen, C.-Y., Neale, B., and Do, R. (2018). Detection of widespread horizontal pleiotropy in causal relationships inferred from Mendelian randomization between complex traits and diseases. Nature Genetics 50(5), 693. doi: 10.1038/s41588-018-0099-7.

66. Vikse, B.E., Irgens, L.M., Leivestad, T., Hallan, S., and Iversen, B.M. (2008). Low birth weight increases risk for end-stage renal disease. J Am Soc Nephrol 19(1), 151-157. doi: 10.1681/asn.2007020252.

67. Vivante, A., and Hildebrandt, F. (2016). Exploring the genetic basis of early-onset chronic kidney disease. Nature Reviews Nephrology 12(3), 133. doi: 10.1038/nrneph.2015.205.

68. Wang, J., Wang, B., Liang, M., Wang, G., Li, J., Zhang, Y., et al. (2018). Independent and combined effect of bilirubin and smoking on the progression of chronic kidney disease. Clinical Epidemiology 10, 121-132. doi: 10.2147/clep.s150687.

69. Wang, T., Huang, T., Li, Y., Zheng, Y., Manson, J.E., Hu, F.B., et al. (2016). Low birthweight and risk of type 2 diabetes: a Mendelian randomisation study. Diabetologia 59(9), 1920-1927. doi: 10.1007/s00125-016-4019-z.

70. Webster, A.C., Nagler, E.V., Morton, R.L., and Masson, P. (2017). Chronic kidney disease. Lancet 389(10075), 1238-1252. doi: 10.1016/s0140-6736(16)32064-5. 
659 71. White, S.L., Perkovic, V., Cass, A., Chang, C.L., Poulter, N.R., Spector, T., et al. (2009). Is Low Birth Weight an Antecedent of CKD in Later Life? A Systematic Review of Observational Studies. American Journal of Kidney Diseases 54(2), 248-261. doi: 10.1053/j.ajkd.2008.12.042.

72. Wingen, A.M., FabianBach, C., Schaefer, F., and Mehls, O. (1997). Randomised multicentre study of a low-protein diet on the progression of chronic renal failure in children. Lancet 349(9059), 1117-1123. doi: 10.1016/s0140-6736(96)09260-4.

73. Yudkin, J.S., Martyn, C.N., Phillips, D.I.W., and Gale, C.R. (2001). Associations of micro-albuminuria with intra-uterine growth retardation. Nephron 89(3), 309-314. doi: 10.1159/000046091.

74. Zanetti, D., Tikkanen, E., Gustafsson, S., Priest, J.R., Burgess, S., and Ingelsson, E. (2018). Birthweight, Type 2 Diabetes Mellitus, and Cardiovascular Disease Addressing the Barker Hypothesis With Mendelian Randomization. Circulation-Genomic and Precision Medicine 11(6). doi: 10.1161/circgen.117.002054.

75. Zeng, P., Yu, X., and Xu, H. (2019). Association between premorbid body mass index and amyotrophic lateral sclerosis: causal inference through genetic approaches. Frontiers in Neurology (in presss). doi: 10.1101/526186.

76. Zeng, P., Yu, X., and Zhou, X. (2019). Birth weight is not causally associated with adult asthma: results from instrumental variable analyses. Scientific Reports 9(1), 7647. doi: 10.1038/s41598-019-44114-5.

77. Zeng, P., and Zhou, X. (2019). Causal Association between Birth Weight and Adult Diseases: Evidence from a Mendelian Randomisation Analysis. Frontiers in Genetics 10, 618. doi: 10.3389/fgene.2019.00618.

683

684

78. Zeng, P., and Zhou, X. (2019). Causal effects of blood lipids on amyotrophic lateral sclerosis: a Mendelian randomization study. Human molecular genetics 28(4), 688-697. doi: 10.1093/hmg/ddy384. 
688 Table 1. Summary information of 20 studies included in the meta-analysis for investigating the relationship between birth weight and chronic 689 kidney disease

\begin{tabular}{|c|c|c|c|c|c|c|c|}
\hline First author (year) & Country & Study design & $N$ & $\begin{array}{l}\text { Exposure } \\
\text { Reference (g) }\end{array}$ & vs & $\begin{array}{c}\text { OR } \\
(95 \% \mathrm{CI}) \\
\end{array}$ & Covariates \\
\hline \multicolumn{8}{|c|}{ Information for the relationship between low birth weight and CKD } \\
\hline Nelson (1998) (Nelson et al., 1998) & USA & cohort study & 308 & $\begin{array}{l}<2,500 \\
2,500 \sim 4,499\end{array}$ & vs & $2.30(0.72 \sim 7.00)$ & age, sex, duration of DM, hemoglobin, $\mathrm{A} 1 \mathrm{c}$, mean arterial $\mathrm{BP}$ \\
\hline Lackland (2000) (Lackland et al., 2000) & USA & case-control & 3,690 & $\begin{array}{l}<2,500 \\
3,000 \sim 3,499\end{array}$ & vs & $1.40(1.10 \sim 1.80)$ & unadjusted \\
\hline $\begin{array}{l}\text { Vasarhelyi (2000) (Vasarhelyi et al., } \\
\text { 2000) }\end{array}$ & Hungary & cohort study & 126 & $\begin{array}{l}<2,500 \\
3,000 \sim 3,999\end{array}$ & vs & $0.71(0.20 \sim 2.80)$ & Sex \\
\hline Lackland (2001) (Lackland et al., 2001) & USA & case-control & 1,230 & $\begin{array}{l}<2,500 \\
3,000 \sim 3,499\end{array}$ & vs & $1.70(1.00 \sim 2.80)$ & unadjusted \\
\hline Yudkin (2001) (Yudkin et al., 2001) & UK & cohort study & 818 & $\begin{array}{l}\text { ponderal index i } \\
\text { lower } 3^{\text {rd }} \text { vs other }\end{array}$ & in & $3.10(0.90 \sim 11.30)$ & age, sex, BMI, SBP, region, fasting glucose \\
\hline Dyck (2003) (Dyck et al., 2003) & Canada & case-control & 878 & $\begin{array}{l}<2,500 \\
2,501 \sim 3,999\end{array}$ & vs & $1.62(0.88 \sim 2.96)$ & unadjusted \\
\hline Painter (2005) (Painter et al., 2005) & Netherlands & cohort study & 724 & $\begin{array}{l}\text { exposure to famine } \\
\text { mid-gestation } \\
\text { non-exposed }\end{array}$ & vs. & $3.22(1.34 \sim 7.65)$ & $\begin{array}{l}\text { age, sex, BMI, smoking, SES, SBP, IGT/NIDDM, cholesterol, } \\
\text { ECG abnormalities }\end{array}$ \\
\hline Fagerudd (2006) (Fagerudd et al., 2006) & Finland & cohort study & 1,543 & $\begin{array}{l}<10 \text { th percentile } \\
50 \text { to } 90 \text { th percentile }\end{array}$ & & $0.99(0.61,1.62)$ & gestational age \\
\hline Fan (2006) (Fan et al., 2006) & USA & cohort study & 7,505 & $\begin{array}{l}<2,500 \\
2,500 \sim 3,999\end{array}$ & vs & $1.56(1.02 \sim 2.39)$ & age, sex, ethnicity, DM, hypertension \\
\hline Salmi (2007) (Al Salmi et al., 2007) & Australia & cohort study & 4,502 & $<2,500$ vs $\geq 2,500$ & & $2.54(1.54 \sim 4.18)$ & unadjusted \\
\hline Haysom (2007) (Haysom et al., 2007) & Australia & cohort study & 1,382 & $\begin{array}{l}<2,500 \\
2,500 \sim 3,999\end{array}$ & vs & $0.95(0.10 \sim 2.12)$ & age, sex, ethnicity, SES \\
\hline Salmi (2008) (Al Salmi et al., 2008) & Australia & cross-control & 567 & $\begin{array}{l}<2,500 \\
3,000 \sim 3,999\end{array}$ & vs & $3.60(1.70 \sim 7.60)$ & $\begin{array}{l}\text { age, sex, diabetes, hypertension, glomerulonephritis, and } \\
\text { Reno-vascular disease }\end{array}$ \\
\hline Hallan (2008) (Hallan et al., 2008) & Norway & cohort study & 7,457 & $\begin{array}{l}<3 \text { rd vs } 10 \text { th-90t } \\
\text { percentile }\end{array}$ & & $1.63(0.76 \sim 3.50)$ & age, smoking, education, maternal factors \\
\hline Li (2008) (Li et al., 2008) & USA & retrospective cohort & 12,364 & $\begin{array}{l}<2,500 \\
3,000 \sim 3,999\end{array}$ & vs & $1.25(0.81 \sim 1.92)$ & $\begin{array}{l}\text { age, race, education, insurance, region, DM, HTN, CVD, family } \\
\text { history of kidney disease, HTN control }\end{array}$ \\
\hline Vikse (2008) (Vikse et al., 2008) & Norway & retrospective cohort & 2.2 million & $\begin{array}{l}<2,500 \\
2,500 \sim 4,499\end{array}$ & vs & $2.00(1.40 \sim 2.80)$ & $\begin{array}{l}\text { sex, birth year, birth order, congenital malformation, multiple } \\
\text { delivery, maternal factors (age, marital status, preeclampsia) }\end{array}$ \\
\hline Oster (2013) (Oster et al., 2013) & Canada & cohort study & 1,439 & $<2,500$ vs $\geq 2,500$ & & $2.36(1.24 \sim 4.49)$ & age and sex \\
\hline Berglund (2014) (Berglund et al., 2014) & USA & case-control & 216 & $<2500$ & & $0.70(0.28 \sim 1.74)$ & age, sex, BMI, time from donation, SBP, DBP \\
\hline
\end{tabular}




\begin{tabular}{|c|c|c|c|c|c|c|c|}
\hline Hirano (2016) (Hirano et al., 2016) & Japan & case-control & $20,620,003$ & \multirow{2}{*}{\multicolumn{2}{|c|}{$\begin{array}{l}<2,500 \text { vs } \geq 2,500 \\
<10 \text { th percentile } \\
\text { vs }>10 \text { th percentile }\end{array}$}} & $4.21(3.37 \sim 5.26)$ & birth year \\
\hline Ruggajo (2016) (Ruggajo et al., 2016) & Norway & retrospective cohort & 471 & & & $1.40(0.69 \sim 2.70)$ & glomerular filtration \\
\hline Eriksson (2018) (Eriksson et al., 2018) & Finland & cohort study & 1,060 & $\begin{array}{l}\leq 2,500 \\
3,000-3,499\end{array}$ & vs & $1.32(0.79 \sim 2.22)$ & unadjusted \\
\hline \multicolumn{8}{|c|}{ Information for the relationship between high birth weight and CKD } \\
\hline Nelson (1998) (Nelson et al., 1998) & USA & cohort study & 308 & $\begin{array}{l}\geq 4,500 \\
2,500 \sim 4,499\end{array}$ & vs & $3.20(0.75 \sim 13.40)$ & age, sex, duration of DM, hemoglobin, A1c, mean arterial BP \\
\hline Lackland (2000) (Lackland et al., 2000) & USA & case-control & 2,690 & $\begin{array}{l}\geq 4,000 \\
3,000 \sim 3,499\end{array}$ & vs & $1.10(0.90 \sim 1.40)$ & unadjusted \\
\hline Dyck (2003) (Dyck et al., 2003) & Canada & case-control & 878 & $\begin{array}{l}>4,000 \\
2,501 \sim 3,999\end{array}$ & vs & $0.74(0.44 \sim 1.20)$ & unadjusted \\
\hline Fagerudd (2006) (Fagerudd et al., 2006) & Finland & cohort study & 1,543 & $\begin{array}{l}>90 \text { th percentile } \\
50 \text { to } 90 \text { th percentil }\end{array}$ & & $1.12(0.60 \sim 2.08)$ & gestational age \\
\hline Fan (2006) (Fan et al., 2006) & USA & cohort study & 7,505 & $\begin{array}{l}\geq 4,000 \\
2,500 \sim 3,999\end{array}$ & vs & $1.29(0.79 \sim 2.09)$ & age, sex, ethnicity, DM, hypertension \\
\hline Li (2008) (Li et al., 2008) & USA & retrospective cohort & 12,364 & $\begin{array}{l}\geq 4,000 \\
3,000 \sim 3,999\end{array}$ & vs & $1.41(1.06 \sim 1.88)$ & $\begin{array}{l}\text { age, race, education, insurance, region, DM, HTN, CVD, family } \\
\text { history of kidney disease, HTN control }\end{array}$ \\
\hline Vikse (2008) (Vikse et al., 2008) & Norway & retrospective cohort & $2.2 \mathrm{M}$ & $\begin{array}{l}\geq 4,000 \\
2,501 \sim 4,499\end{array}$ & vs & $3.20(0.75 \sim 13.40)$ & $\begin{array}{l}\text { sex, birth year, birth order, congenital malformation, multiple } \\
\text { delivery, maternal factors (age, marital status, preeclampsia) }\end{array}$ \\
\hline Oster (2013) (Oster et al., 2013) & Canada & cohort study & 1,439 & $\geq 4,000$ vs $\geq 2,500$ & & $0.56(0.23 \sim 1.38)$ & age and sex \\
\hline Eriksson (2018) (Eriksson et al., 2018) & Finland & cohort study & 20,431 & $\begin{array}{l}\geq 4,000 \\
3,000-3,499\end{array}$ & vs & $0.59(0.39 \sim 1.00)$ & unadjusted \\
\hline \multicolumn{8}{|c|}{ Information for the relationship between low birth weight and CKD for male } \\
\hline Lackland (2000) (Lackland et al., 2000) & USA & case-control & 2,676 & $\begin{array}{l}<2,500 \\
3,000 \sim 3,499\end{array}$ & vs & $1.20(0.90 \sim 1.60)$ & unadjusted \\
\hline Dyck (2003) (Dyck et al., 2003) & Canada & case-control & 183 & $\begin{array}{l}<2,500 \\
2,501 \sim 3,999\end{array}$ & vs & $1.12(0.50 \sim 2.52)$ & unadjusted \\
\hline Salmi (2007) (Al Salmi et al., 2007) & Australia & cohort study & NA & $<2,500$ vs $\geq 2,500$ & & $3.40(2.11 \sim 5.36)$ & unadjusted \\
\hline Hallan (2008) (Hallan et al., 2008) & Norway & cohort study & 3,534 & $\begin{array}{l}<2,450 \\
2,870-4,190\end{array}$ & vs & $2.68(1.58 \sim 4.51)$ & age, smoking, education, maternal factors \\
\hline Li (2008) (Li et al., 2008) & USA & retrospective cohort & 2,920 & $\begin{array}{l}<2,500 \\
3,000 \sim 3,999\end{array}$ & vs & $1.65(0.90 \sim 1.25)$ & $\begin{array}{l}\text { age, race, education, insurance, region, DM, HTN, CVD, family } \\
\text { history of kidney disease, HTN control }\end{array}$ \\
\hline Vikse (2008) (Vikse et al., 2008) & Norway & retrospective cohort & $1,120,789$ & $\begin{array}{l}<2,500 \\
2,501 \sim 4,499\end{array}$ & vs & $1.50(0.89 \sim 2.40)$ & $\begin{array}{l}\text { sex, birth year, birth order, congenital malformation, multiple } \\
\text { delivery, maternal factors (age, marital status, preeclampsia) }\end{array}$ \\
\hline Ruggajo (2016) (Ruggajo et al., 2016) & Norway & retrospective cohort & 322 & $\begin{array}{l}<10 \text { th percent } \\
\text { vs }>10 \text { th percentile }\end{array}$ & & $1.10(0.52 \sim 2.40)$ & glomerular filtration \\
\hline Eriksson (2018) (Eriksson et al., 2018) & Finland & cohort study & 572 & $\begin{array}{l}\leq 2,500 \\
3,000-3,499\end{array}$ & vs & $1.00(0.49 \sim 1.99)$ & unadjusted \\
\hline \multicolumn{8}{|c|}{ Information for the relationship between low birth weight and CKD for female } \\
\hline Lackland (2000) (Lackland et al., 2000) & USA & cross-control & 1,014 & $\begin{array}{l}<2,500 \\
3,000 \sim 3,499\end{array}$ & vs & $1.90(1.20 \sim 3.00)$ & unadjusted \\
\hline Dyck (2003) (Dyck et al., 2003) & Canada & cross-control & 130 & $\begin{array}{l}<2,500 \\
2,501 \sim 3,999\end{array}$ & vs & $2.70(1.05 \sim 6.95)$ & unadjusted \\
\hline
\end{tabular}




\begin{tabular}{|c|c|c|c|c|c|c|}
\hline Salmi (2007) (Al Salmi et al., 2007) & Australia & cohort study & NA & $<2,500$ vs $\geq 2,500$ & $2.04(1.45 \sim 2.88)$ & unadjusted \\
\hline Hallan (2008) (Hallan et al., 2008) & Norway & cohort study & 3,923 & $\begin{array}{l}<2,450 \\
2,870-4,190\end{array}$ & $1.01(0.54 \sim 1.90)$ & age, smoking, education, maternal factors \\
\hline Li (2008) (Li et al., 2008) & USA & retrospective cohort & 9,444 & $\begin{array}{l}<2,500 \\
3,000 \sim 3,999\end{array}$ & $1.07(0.81 \sim 1.92)$ & $\begin{array}{l}\text { age, race, education, insurance, region, DM, HTN, CVD, family } \\
\text { history of kidney disease, HTN control }\end{array}$ \\
\hline Vikse (2008) (Vikse et al., 2008) & Norway & retrospective cohort & $1,061,909$ & $\begin{array}{l}<10 \text { th percentile vs } \\
10 \text { to } 90 \text { th percentile }\end{array}$ & $2.80(1.80 \sim 4.40)$ & $\begin{array}{l}\text { Sex, birth year, birth order, congenital malformation, multiple } \\
\text { delivery, maternal factors (age, marital status, preeclampsia) }\end{array}$ \\
\hline Ruggajo (2016) (Ruggajo et al., 2016) & Norway & retrospective cohort & 139 & $\begin{array}{l}<10 \text { th percentile } \\
\text { vs }>10 \text { th percentile }\end{array}$ & $1.40(0.32-6.40)$ & glomerular filtration \\
\hline Eriksson (2018) (Eriksson et al., 2018) & Finland & cohort study & 488 & $\begin{array}{l}\leq 2,500 \\
3,000-3,499\end{array}$ & $1.99(1.00 \sim 4.30)$ & unadjusted \\
\hline
\end{tabular}

690 Note: BMI: body mass index; DM: diabetes mellitus; SBP: systolic blood pressure; HTN: hypertension; CVD: cerebrovascular disease; PSGN: post streptococcal glomerulonephritis. 
691 Fig. 1. Combined effect of birth weight on CKD in the meta-analysis based on

692 observational studies. (A) Combined effect for individuals with low birth weight 693 compared with those with normal birth weight based on twenty studies; (B) Combined 694 effect for individuals with high birth weight compared with those with normal birth 695 weight based on nine studies. 
696 Fig. 2. (A) Relationship between the SNP effect size estimates of birth weight (x-axis)

697 and the corresponding effect size estimates of CKD (y-axis). In the plot, the 95\% CIs

698 for the effect sizes of instruments on birth weight are shown as horizontal lines, while

699 the $95 \%$ CIs for the effect sizes of instruments on CKD are shown as vertical lines.

700 The line in red represents the estimated causal effect of birth weight on CKD obtained

701 using the IVW method while the blue line represents the estimated causal effect

702 produced by the MR-Egger regression. (B) Funnel plot for single causal effect

703 estimate of birth weight on CKD; the horizontal dot line denotes the estimated causal 704 effect with IVW. 
705 Fig. 3. Statistical power estimated with the analytic method shown in (Brion et al., 706 2013). In the estimation, the total phenotypic variance explained by instrumental 707 variables was set to be $0.91 \%$, the significance level $\alpha$ was set to be 0.05 , the 708 proportion of CKD cases was set to be from 0.1 to 0.5 . Two situations of sample size 709 (i.e. 117,000 and 200,000) were considered. For each situation, the OR was assumed 710 to be 0.80 or 0.90 , respectively. 
A

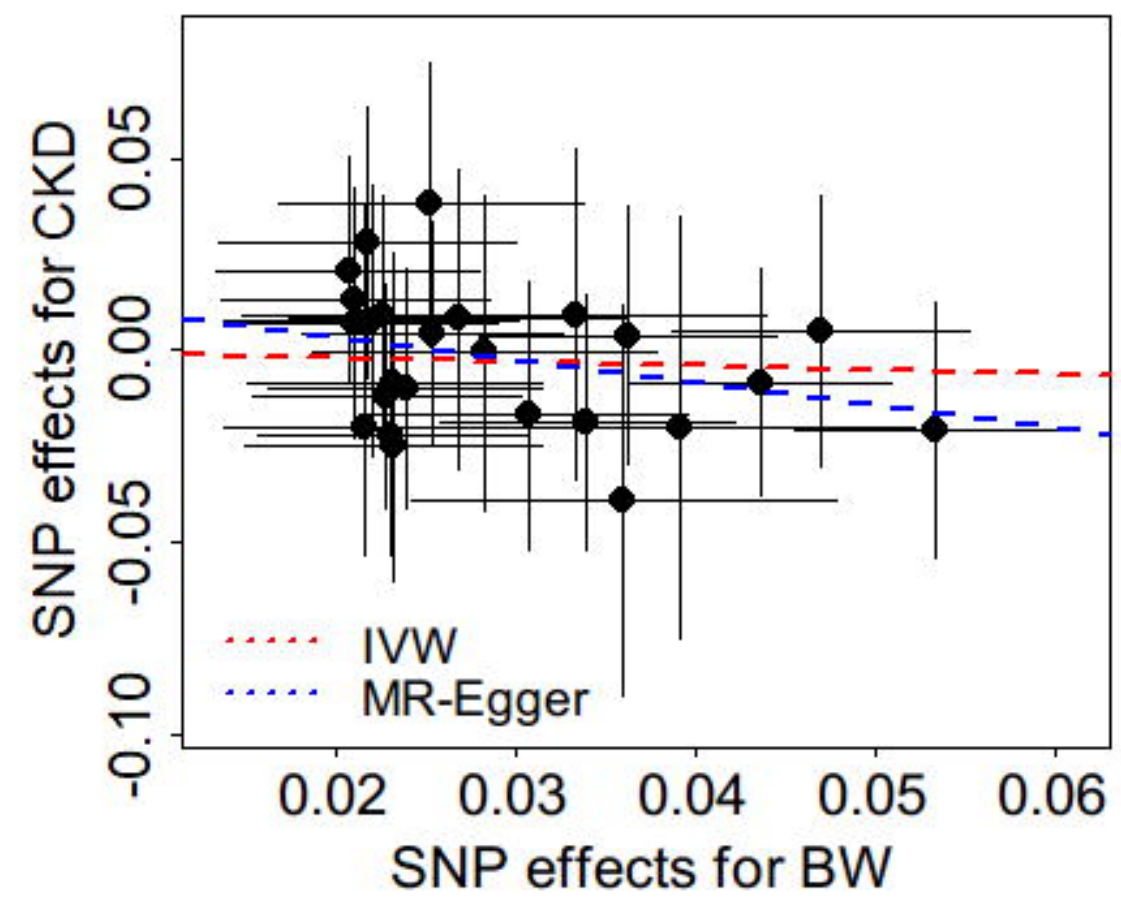

B

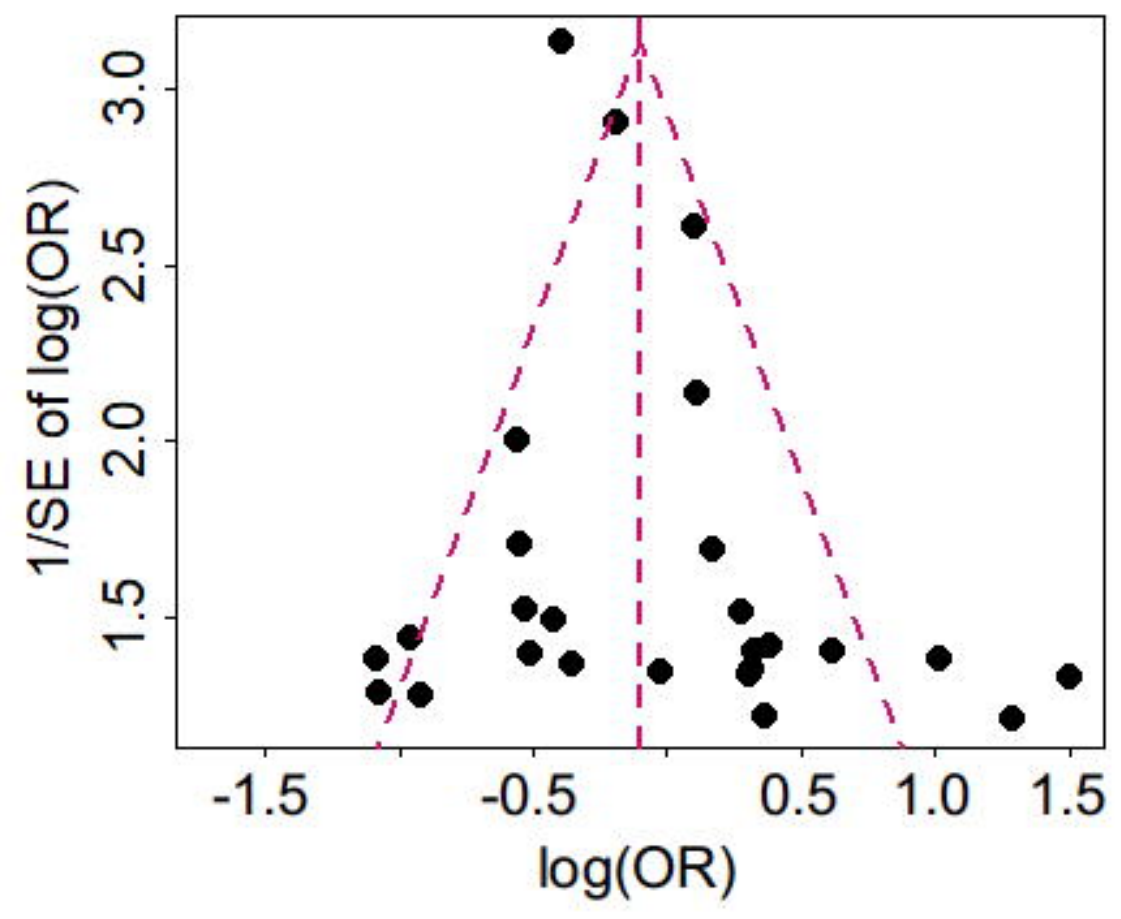




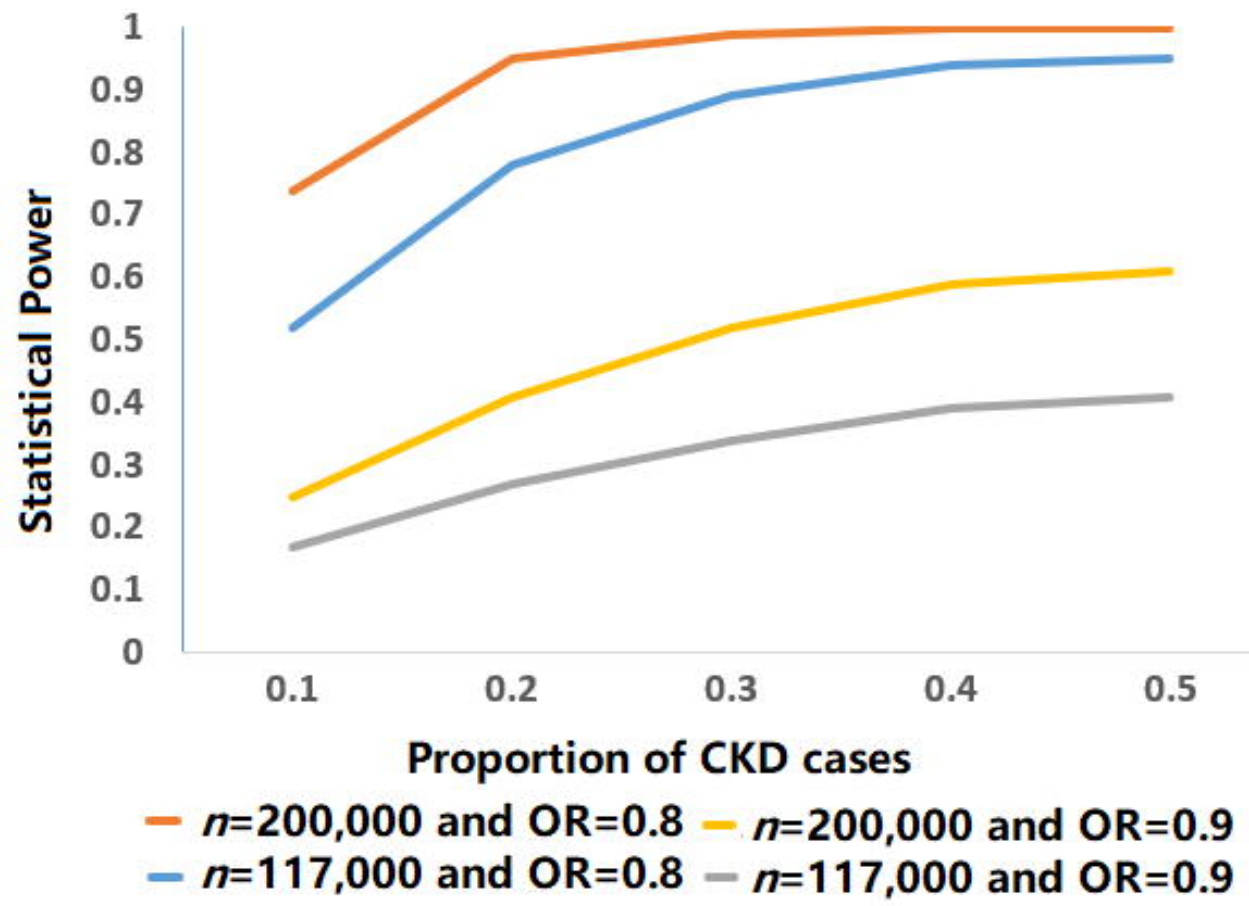


1998 Nelson et al

2000 Lackland et al

2000 Vasarhelyi et al

2001 Lackland et al

2001 Yudkin et al

2003 Dyck et al

2005 Painter et al

2006 Fagerudd et al

2006 Fan et al

2007 Salmi et al

2007 Haysom et al

2008 Salmi et al

2008 Hallan et al

$2008 \mathrm{Li}$ et al

2008 Vikse et al

2013 Oster et al

2014 Berglund et al

2016 Hirano et al

2016 Ruggajo et al

2018 Eriksson et al

$\begin{array}{rr}0.83 & 0.59 \\ 0.34 & 0.13 \\ -0.34 & 0.65 \\ 0.53 & 0.26 \\ 1.13 & 0.64 \\ 0.48 & 0.31 \\ 1.17 & 0.44 \\ -0.01 & 0.25 \\ 0.44 & 0.22 \\ 0.93 & 0.26 \\ -0.05 & 0.78 \\ 1.28 & 0.38 \\ 0.49 & 0.39 \\ 0.22 & 0.22 \\ 0.69 & 0.18 \\ 0.86 & 0.33 \\ -0.36 & 0.47 \\ 1.44 & 0.11 \\ 0.34 & 0.35 \\ 0.28 & 0.26\end{array}$

2.30

1.40

[0.73; 7.27]

0.71

1.70

3.10

1.62

3.22

0.99

1.56

2.54

0.95

3.60

1.63

1.25

2.00

2.36

0.70

4.21

1.40

1.32
$[0.20 ; 2.53]$

$[1.02 ; 2.85]$

$[0.88 ; 10.97]$

$[0.88 ; 2.97]$

$[1.35 ; 7.68]$

$[0.61 ; 1.61]$

$[1.02 ; 2.39]$

$[1.54 ; 4.19]$

$[0.21 ; 4.37]$

$[1.70 ; 7.61]$

$[0.76 ; 3.50]$

$[0.81 ; 1.92]$

$[1.41 ; 2.83]$

$[1.24 ; 4.49]$

$[0.28 ; 1.74]$

$[3.37 ; 5.26]$

$[0.71 ; 2.77]$

$[0.79 ; 2.22]$
[1.09; 1.79]

$3.0 \%$

$7.2 \%$

$2.6 \%$

$5.8 \%$

$2.6 \%$

$5.3 \%$

$4.0 \%$

$6.0 \%$

$6.3 \%$

$5.9 \%$

$2.0 \%$

$4.6 \%$

$4.5 \%$

$6.3 \%$

$6.7 \%$

$5.1 \%$

$3.8 \%$

$7.3 \%$

$4.9 \%$

$5.8 \%$

$1.76[1.37 ; 2.26] 100.0 \%$

Random effects model

Heterogeneity: $I^{2}=77 \%, \tau^{2}=0.2160, p<0.01$

$\begin{array}{lllll}0.1 & 0.5 & 1 & 2 & 10\end{array}$

10

Study

Beta seBeta

1.16

0.10

2000 Lackland et al

$-0.30$

0.11

0.26

0.34

1.16

$-0.58$

$-0.55$
0.74

0.11

0.26

0.32

0.25

0.15

0.74

0.46

Odds Ratio

0.25
OR

3.20

$[0.76 ; 13.51]$

$[0.88 ; 1.37]$

0.74

$[0.45 ; 1.22]$

$1.12[0.60 ; 2.08]$

1.29

$[0.79 ; 2.10]$

$1.41[1.06 ; 1.88]$

$3.20[0.76 ; 13.51]$

$0.56[0.23 ; 1.37]$

$0.58 \quad[0.36 ; 0.94]$
$2.9 \%$

$20.3 \%$

$12.7 \%$

$10.2 \%$

$13.1 \%$

$18.5 \%$

$2.9 \%$

$6.3 \%$

$13.1 \%$ 